\title{
A Case of Brunner's Gland Hyperplasia: Endoscopic Color Doppler Ultrasonographic Findings
}

Brunner's gland hyperplasia, which shows the features of a submucosal tumor, is a rare duodenal tumor that presents with characteristic symptoms, such as massive bleeding (1-3). Little is known about the findings on endoscopic ultrasonographic (EUS) B-mode and color Doppler imaging.

A 48-year-old man was referred to our hospital due to abnormal findings at upper gastrointestinal radiography during a routine examination. An endoscopic examination demonstrated a submucosal lesion, $3 \mathrm{~cm}$ in diameter, which was identified as a polypoid tumor with a wide base at the anterior side of the duodenum (Figure 1). An EUS examination using the balloon method with an EPE-703 FL (Toshiba-Machida Co. Ltd., Tokyo, Japan) demonstrated a subtle hypoechoic heterogeneous lesion located in the submucosal layer, with associated cystic changes. On the color Doppler study, abundant color signals were seen in the lesion (Figure 2). Using a fast Fourier transform analysis, these visualized signals mainly appeared as continuous and pulsatile wave forms

Angiography showed a hypervascular tumor, fed by the gastroduodenal artery. Based on these findings, it was thought that endoscopic resection carried too high a risk of bleeding, and surgical resection of the polyp to the depth of the submucosal layer was carried out. Just after the resection, arterial bleeding from the cut surface occurred. Histologically, the lesion was confirmed as Brunner's gland hyperplasia.

With regard to the treatment, it has been reported that endoscopic excision offers a safe alternative to surgical resection $(4,5)$. However, precautions must be taken to prevent bleeding during and following resection, since such lesions are usually hypervascular. Surgical procedure should particularly be recommended for cases in which rich arterial flow is evident in the lesion. Endoscopic color Doppler ultrasonography, which can visualize the blood flow in the tumor, and determination of the wave patterns using FFT analysis, can facilitate selection of the appropriate treatment. When the tumor was resected in our patient, arterial bleeding occurred, necessitating a clipping maneuver. Endoscopic color Doppler ultrasonography proved to be useful both in the diagnosis and in the selection of appropriate treatment for this lesion.

N. Ueno, T. Tomiyama, S. Tano, T. Aizawa, N. Nagamine, K. Kihira, Y. Kumakura, Y. Ishino, K. Kimura

Dept. of Gastroenterology, Jichi Medical School, Tochigi, Japan

\section{References}

I. Levine JA, Burgart LJ, Batts KP, et al. Brunner's gland hamartomas: clinical presentation and pathological features of 27 cases. Am J Gastroenterol 1995; 90: 290-4.

2. Kouraklis G, Kostakis A, Delladetsima J. Hamartoma of Brunner's glands causing massive haematemesis. Scand J Gastroenterol 1994; 29: 841-3.

3. Schluger LK, Rotterdam H, Lebwohl O. Gastrointestinal hemorrhage from a Brunner's gland hamartoma. Am J Gastroenterol 1994: 89: 2088-9.

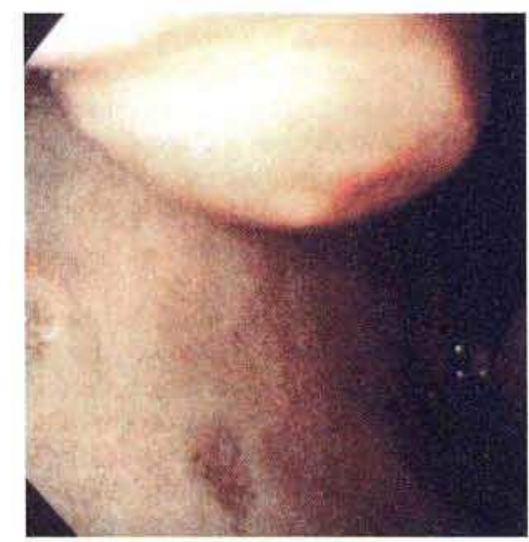

Figure 1: Endoscopic image of a submucosal lesion, measuring $3 \mathrm{~cm}$, identified as a polypoid tumor with a wide base on the anterior side of the duodenum.

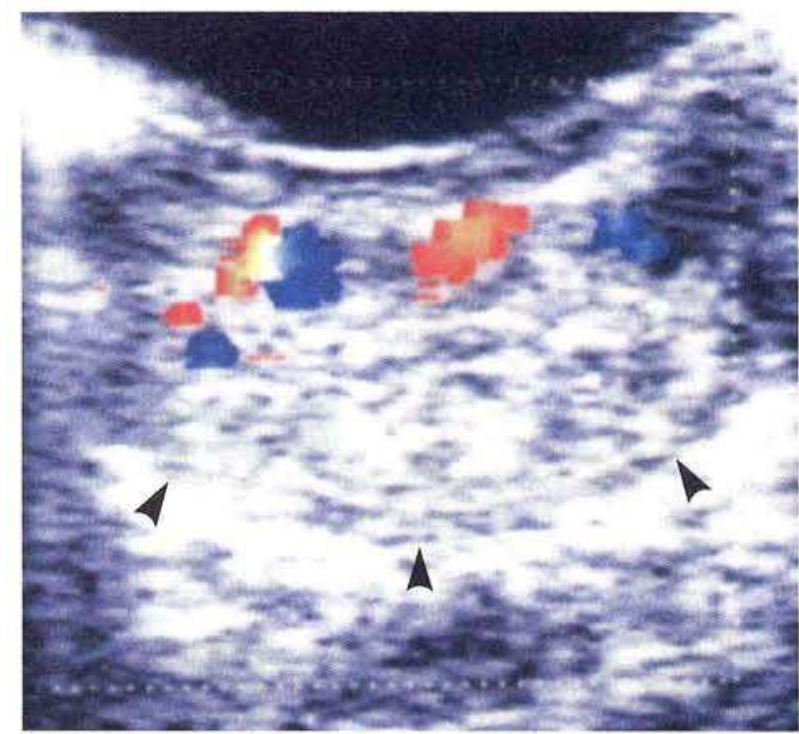

Figure 2: Endoscopic ultrasonographic examination of the duodena tumor by the balloon method showed a subtle hypoechoic heterogeneous lesion located in the submucosal layer (arrowheads). Abundant color signals were demonstrated in the lesion using the color Doppler mode.

4. Appel MF, Bentlif PS. Endoscopic removal of bleeding Brunner gland adenoma. Arch Surg 1976; 111: 301 .

5. Peetz ME, Moseley HS. Brunner's gland hyperplasia. Am Surg $1989 ; 55: 474-7$.

Corresponding Author

N. Ueno, M.D.

Dept. of Gastroenterology

Jichi Medical School

Yakushiji

Tochigi 329-04

Japan

Fax: +81-2 85-44-8297 